\title{
APPROXIMATION OF COMMON SOLUTIONS TO PROXIMAL SPLIT FEASIBILITY PROBLEMS AND FIXED POINT PROBLEMS
}

\author{
YEKINI SHEHU \\ Department of Mathematics, University of Nigeria, Nsukka, Nigeria \\ E-mail: yekini.shehu@unn.edu.ng
}

\begin{abstract}
This paper is concerned with an algorithmic solution to the proximal split feasibility problem which is also a fixed point of a $k$-strictly pseudocontractive mapping in Hilbert spaces. Under some assumptions on the parameters in our iterative algorithm, we first establish a strong convergence theorem for a problem of finding a point which minimizes a proper convex lower-semicontinuous function $f$ which is also a fixed point of a $k$-strictly pseudocontractive mapping such that its image under a bounded linear operator $A$ minimizes another proper convex lower-semicontinuous function $g$ and secondly prove another strong convergence result for a problem of finding a point which minimizes a proper convex lower-semicontinuous function $f$ which is also a fixed point of a $k$-strictly pseudocontractive mapping such that its image under a bounded linear operator $A$ minimizes locally lower semicontinuous, prox-bounded and prox-regular function $g$. In all our results in this work, our iterative schemes are proposed with a way of selecting the step-sizes such that their implementation does not need any prior information about the operator norm because the calculation or at least an estimate of the operator norm $\|A\|$ is very difficult, if it is not an impossible task. Our result complement many recent and important results in this direction.

Key Words and Phrases: proximal split feasibility problems, Moreau-Yosida approximate, proxregularity, $k$-strictly pseudocontractive mapping, fixed point, strong convergence, Hilbert spaces.

2010 Mathematics Subject Classification: 49J53, 65K10, 49M37, 47H10, 90C25.
\end{abstract}

Acknowledgements. The research was carried out when the author was an Alexander von Humboldt Postdoctoral Fellow at the Institute of Mathematics, University of Wurzburg, Germany. He is grateful to the Alexander von Humboldt Foundation, Bonn for the fellowship and the Institute of Mathematics, University of Wurzburg, Germany for the hospitality and facilities.

\section{REFERENCES}

[1] G. Lopez Acedo, H.-K. Xu, Iterative methods for strict pseudo-contractions in Hilbert spaces, Nonlinear Anal., 67(2007), 2258-2271.

[2] F.E. Browder, W.V. Petryshyn, Construction of fixed points of nonlinear mappings in Hilbert space, J. Math. Anal. Appl., 20(1967), 197-228.

[3] C. Byrne, Iterative oblique projection onto convex sets and the split feasibility problem, Inverse Problems, 18(2002), no. 2, 441-453.

[4] C. Byrne, A unified treatment of some iterative algorithms in signal processing and image reconstruction, Inverse Problems, 20(2004), no. 1, 103-120. 
[5] C. Byrne, Y. Censor, A. Gibali, S. Reich, The Split Common Null Point Problem, J. Nonlinear Convex Anal., 13(2012), no. 4, 759-775.

[6] L.C. Ceng, S. Al-Homidan, Q.H. Ansari, J.C. Yao, An iterative scheme for equilibrium problems and fixed point problems of strict pseudo-contraction mappings, J. Comput. Appl. Math., 223(2009), 967-974.

[7] Y. Censor, T. Elfving, A multiprojection algorithm using Bregman projections in a product space, Numerical Algorithms, 8(1994), no. 2-4, 221-239.

[8] C.E. Chidume, M. Abbas, B. Ali, Convergence of the Mann iteration algorithm for a class of pseudo-contractive mappings, Appl. Math. Comput., 194(2007), 1-6.

[9] P. Cholamjiak, S. Suantai, Strong convergence for a countable family of strict pseudocontractions in q-uniformly smooth Banach spaces, Comput. Math. Appl., 62(2011), 787-796.

[10] Y. Hao, S. Y. Cho, Some results on strictly pseudocontractive nonself mapping and equilibrium problems in Hilbert spaces, Abst. Appl. Anal., vol. 2012, Article ID 543040, 14 pages.

[11] C. Jaiboon, P. Kumam, Strong convergence theorems for solving equilibrium problems and fixed point problems of strictly pseudocontraction mappings by two hybrid projection methods, J. Comput. Appl. Math., 234(2010), no. 3, 722-732.

[12] J.S. Jung, Iterative methods for mixed equilibrium problems and psedocontractive mappings, Fixed Point Theory and Appl., 2012 2012:184.

[13] Y. Liu, A general iterative method for equilibrium problems and strict pseudo-contractions in Hilbert spaces, Nonlinear Anal., 71(2009), 4852-4861.

[14] G. Lopez, V. Martin-Marquez, F. Wang, H.K. Xu, Solving the split feasibility problem without prior knowledge of matrix norms, Inverse Problems, 28(2012), 085004.

[15] D.R. Luke, J.V. Burke, R.G. Lyon, Optical wavefront reconstruction: theory and numerical methods, SIAM Rev., 44(2002), 169-224.

[16] G. Marino, H.-K. Xu, Weak and strong convergence theorems for strict pseudo-contractions in Hilbert spaces, J. Math. Anal. Appl., 329(2007), 336-346.

[17] P.E. Maingé, The viscosity approximation process for quasi-nonexpansive mappings in Hilbert spaces, Comput. Math. Appl., 59(2010), 74-79.

[18] A. Moudafi, Split monotone variational inclusions, J. Optim. Theory Appl., 150(2011), no. 2, $275-283$.

[19] A. Moudafi, B.S. Thakur, Solving proximal split feasibility problems without prior knowledge of operator norms, Optim. Lett., 8(2014), 2099-2110.

[20] M.O. Osilike, Y. Shehu, Cyclic algorithm For common fixed points of finite family of strictly pseudocontractive mappings of Browder-Petryshyn type, Nonlinear Anal., 70(2009), 3575-3583.

[21] L-J. Qin, L. Wang, An iteration method for solving equilibrium problems, common fixed point problems of pseudocontractive mappings of Browder-Petryshyn type in Hilbert spaces, Int. Math. Forum, 6(2011), no. 2, 63-74.

[22] B. Qu, N. Xiu, A note on the CQ algorithm for the split feasibility problem, Inverse Problems, 21(2005), no. 5, 1655-1665.

[23] Y. Shehu, Iterative methods for family of strictly pseudocontractive mappings and system of generalized mixed equilibrium problems and variational inequality problems, Fixed Point Theory Appl., volume 2011 (2011), Article ID 852789, 17 pages.

[24] Y. Shehu, Iterative methods for convex proximal split feasibility problems and fixed point problems, Afr. Mat., 27 (2016), no. 3, 501-517.

[25] Y. Shehu, F.U. Ogbuisi, Convergence analysis for proximal split feasibility problems and fixed point problems, J. Appl. Math. Comput., 48(2015), 221-239.

[26] H.-K. Xu, Iterative methods for the split feasibility problem in infinite-dimensional Hilbert spaces, Inverse Problems, 26(2010), no. 10, Article ID 105018.

[27] H.-K. Xu, A variable Krasnosel'skii-Mann algorithm and the multiple-set split feasibility problem, Inverse Problems, 22(2006), no. 6, 2021-2034.

[28] H.K. Xu, Iterative algorithm for nonlinear operators, J. London Math. Soc., 66(2002), no. 2, $1-17$.

[29] Q. Yang, The relaxed $C Q$ algorithm solving the split feasibility problem, Inverse Problems, 20(2004), no. 4, 1261-1266. 
[30] Q. Yang, J. Zhao, Generalized KM theorems and their applications, Inverse Problems, 22(2006), no. 3, 833-844.

[31] Y. Yao, R. Chen, Y.-C. Liou, A unified implicit algorithm for solving the triple-hierarchical constrained optimization problem, Math. Comput. Model., 55(2012), no. 3-4, 1506-1515.

[32] Y. Yao, Y.-J. Cho, Y.-C. Liou, Hierarchical convergence of an implicit double net algorithm for nonexpansive semigroups and variational inequalities, Fixed Point Theory Appl., vol. 2011, article 101.

[33] Y. Yao, W. Jigang, Y.-C. Liou, Regularized methods for the split feasibility problem, Abstr. Appl Anal., vol. 2012, Article ID 140679, 13 pages.

[34] Y. Yao, Y.-C. Liou, S. M. Kang, Two-step projection methods for a system of variational inequality problems in Banach spaces, J. Global Optim., 55(2013), no. 4, 801-811.

[35] J. Zhao, Q. Yang, Several solution methods for the split feasibility problem, Inverse Problems, 21(2005), no. 5, 1791-1799.

[36] H. Y. Zhou, Convergence theorems of fixed points for strict pseudo-contractions in Hilbert spaces, Nonlinear Anal., 69(2008), no. 2, 456-462.

Received: March 19, 2014; Accepted: June 16, 2015. 